\title{
SYNTHESIS OF METHYL, BENZYL AND PSEUDO-HALOGENO CO (III) COMPLEXES OF A DIOXIME CONTAINING A CROWN ETHER MOIETY
}

\author{
SangeetaSahu \\ Department of Applied Chemistry, Bhila iInstitute of Technology, Kendri, New Raipur-493661 (Chhattisgarh) INDIA \\ sangeetasahu76@gmail.com
}

\begin{abstract}
In view of the importance of the macrocyclic chemistry, the Cobalt (II) complexes of several new categories of azamacrocycles were synthesized. Here we describes a new quadridentate ligand 5,6-Benzo(15-crown-5)4,7-diaza deca-2,9-ethanedial dioxime $\left(\mathrm{C}_{18} \mathrm{H}_{24} \mathrm{~N}_{4} \mathrm{O}_{7}\right)$. This chelate coordinates with cobalt in the equatorial position as a monoanion leaving the axial sites vacant for coordination by a variety of monodentate ligands, thereby paving the way for the synthesis of pseudo halogeno and alkyl Co(III) complexes. The macrocyclic ligands and their complexes have been characterized by elemental analysis, molecular weight determination, conductance, IR and NMR spectral studies. The spectral data suggested tetra coordinated state for cobalt, its geometry is tetrahedral. Conductivity data suggests that they behave as electrolytes. The formulation of the complexes has been established on the basis of chemical composition. Further analysis for $\mathrm{C}, \mathrm{H}$, and $\mathrm{N}$ and may be required for complete description of the complexes. The ligand and their complexes have been used as catalyst in many industries.
\end{abstract}

Keywords: Cobalt, Macrocyclic complex, synthesis, spectroscopy

\section{INTRODUCTION}

Crown ether compounds, first synthesized by Pederson, who described ${ }^{(1)}$ their ion binding properties have been a focus of interest. This is because of their possible chemical and biological application and their unusual binding capacity, salvation and transport effect. ${ }^{(2)}$

Vic -Dioximes containing mildly acidic hydroxyl groups and slightly basic nitrogen atoms are amphoteric and their transition metal complexes have widely studied as analytical reagents ${ }^{(3)}$.They have also been examined as compounds with columnar stacking which is thought to be the reason for their semiconducting properties ${ }^{(4)}$. Here we describes a new quadridentate ligand 5,6-Benzo(15-crown-5)4,7-diaza deca2,9-ethanedial dioxime $\left(\mathrm{C}_{18} \mathrm{H}_{24} \mathrm{~N}_{4} \mathrm{O}_{7}\right)$. This chelate coordinates with cobalt in the equatorial position as a monoanion leaving the axial sites vacant for coordination by a variety of monodentate ligands, thereby paving the way for the synthesis of pseudo halogeno and alkyl Co(III) complexes.

\section{EXPERIMENTAL}

4,5-Diamino benzo (15-crown-5) was prepared according to a reported method(5).

\subsection{Materials and methods}

In view of the importance of macro cyclic chemistry, the $\mathrm{Co}$ (III) complexes of new categories of aza macro cyclic were synthesized. Template condensation of ethane dionemonoxime was dissolved in water at $60 \mathrm{oC}$ under nitrogen atmosphere. 4,5-diamino benzo 915-crown-5)was added in small portion to this solution and ethanol was then added to reaction mixture, which was stirred at $450 \mathrm{C}$ for $18 \mathrm{hrs}$, then under reflex for one hour. After cooling to $5 \mathrm{oC}$ the mixture was filtered, washed with water coldethanol and ether and then dried in vacuo to yield the corresponding metal complex of the following yellow colored solid macro cyclic legend - 5,6-Benzo(15crown-5)4,7-diaza deca-2,9-ethanedial dioxime (C18H24N4O7).

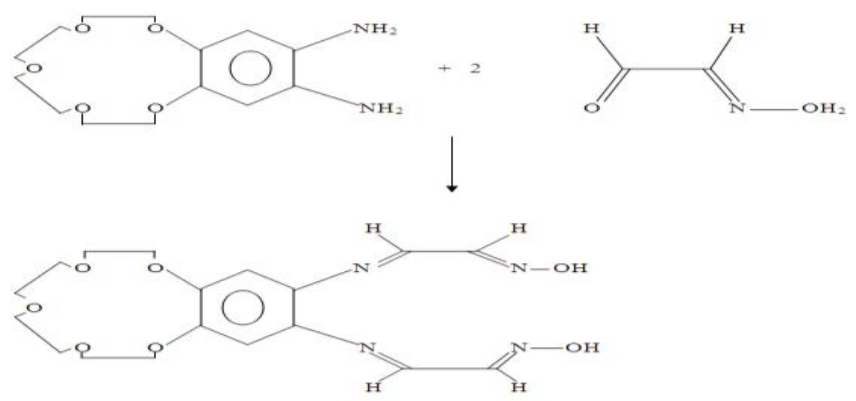


Macro cyclic legend - 5,6-Benzo(15-crown-5)4,7-diaza deca2,9-ethanedial dioxime (C18H24N4O7). Or (H2L)

\subsection{Materials}

Solvents and reagents used in the synthesis of Co (III) complexes were reagent grade and were used without further purification.

\subsection{Synthesis of [Co $(\mathrm{C} 18 \mathrm{H} 23 \mathrm{~N} 4 \mathrm{O}) \mathrm{Br} 2]$ :}

A solution of $\mathrm{CoBr} 2.6 \mathrm{H} 2 \mathrm{O}(3.27 \mathrm{~g}, 10 \mathrm{mmol})$ in dry acetone $(30 \mathrm{ml})$ was added drop wise to a solution of the free ligand of air was then used to agitate the solution for vigorous stirring for two hours. The dark green solution was filtered to remove undisclosed particles and allow to stand overnight at room temperature. The dark green crystalline mass was filtered, washed with dry acetone followed by dry ether and collected under vacuum over dried anhydrous calcium chloride.

13C $\{$ NMte 9DMSO-d6) $\delta-144.54,143.19,140.79,127.38$; 97.81, 62.35-60.15; 10.47; Yield (3.25 g, 79.65\%)

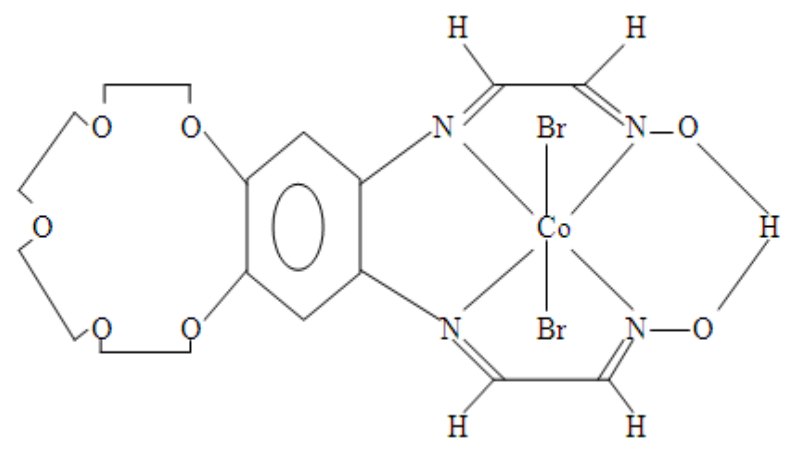

Structure of $\left[\mathrm{Co}\left(\mathrm{C}_{18} \mathrm{H}_{23} \mathrm{~N}_{4} \mathrm{O}_{7}\right) \mathrm{Br}_{2}\right]$

\subsection{Synthesis of [Co $(\mathrm{C18H} 23 \mathrm{~N} 4 \mathrm{O} 7)(\mathrm{NCS})(\mathrm{Br})$ :}

A green solution of [Co $(\mathrm{C} 18 \mathrm{H} 23 \mathrm{~N} 4 \mathrm{O} 7) \mathrm{Br} 2](0.63 \mathrm{~g}, 1 \mathrm{mmol})$ in aqueous hot methyl alcohol (1:8) (20ml) with stirring at $600 \mathrm{C}$ for one hour. The volume of the reaction mixture was then allowed to stand overnight in the refrigerator at ooC. The resulting pale green crystalline product was filtered off, washed with cold water and cold ethanol and then dried in vacuo. The product was recrystallised from methanol,

$13\{\mathrm{C}\}$ $\mathrm{H}$ $142.88 ; 142.22,140.93 ; 128.40 ; 100.44,62.17$ 60.01;16.93,10.75; Yield (0.460GM;66.23\%).

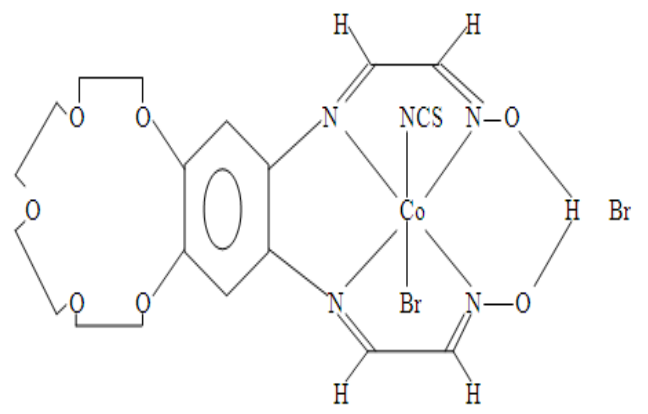

Structure of $\left[\mathrm{Co}\left(\mathrm{C}_{18} \mathrm{H}_{23} \mathrm{~N}_{4} \mathrm{O}_{7}\right)(\mathrm{NCS})(\mathrm{Br})\right.$

\section{RESULT AND DISCUSSION:}

\subsection{Chemical analysis}

Microanalysis for carbon, hydrogen and nitrogen were carried out at the regional sophisticated instrumentation centre, central drug research institute (CDRI) Lucknow.(Table-1.1)

Table 1.1: Analytical and physical data for the dioxime and its complexes

\begin{tabular}{|c|c|c|c|c|c|c|c|}
\hline \multirow[t]{2}{*}{$\begin{array}{l}\text { Compou } \\
\text { nd }\end{array}$} & \multirow[t]{2}{*}{$\begin{array}{l}\text { Col } \\
\text { our }\end{array}$} & \multirow{2}{*}{$\begin{array}{l}\text { Yield } \\
(\%), \\
\text { M.P. } \\
\text { C }\end{array}$} & \multirow[t]{2}{*}{$\begin{array}{l}\text { M } \\
+\end{array}$} & \multicolumn{4}{|c|}{$\begin{array}{l}\% \text { Found } \\
\text { Calculated) }\end{array}$} \\
\hline & & & & $\mathbf{C}$ & $\mathbf{H}$ & $\mathbf{N}$ & $\mathbf{M}$ \\
\hline $\begin{array}{l}\left(\mathrm{C}_{18} \mathrm{H}_{24} \mathrm{~N}\right. \\
\left.{ }_{4} \mathrm{O}_{7}\right) . \quad \text { Or } \\
\left(\mathrm{H}_{2} \mathrm{~L}\right)\end{array}$ & $\begin{array}{l}\text { Pal } \\
\text { e } \\
\text { yell } \\
\text { ow }\end{array}$ & $162^{\circ} \mathrm{C}$ & $\begin{array}{l}4 \\
0 \\
9\end{array}$ & $\begin{array}{l}(52 \\
.94 \\
) \\
52 . \\
80\end{array}$ & $\begin{array}{l}(5 . \\
88) \\
5.7 \\
2\end{array}$ & $\begin{array}{l}(13 . \\
72) \\
13.6 \\
0\end{array}$ & - \\
\hline $\begin{array}{l}\mathrm{Co} \\
\left(\mathrm{C}_{18} \mathrm{H}_{23} \mathrm{~N}\right. \\
\left.{ }_{4} \mathrm{O}_{7}\right) \mathrm{Br}_{2}\end{array}$ & $\begin{array}{l}\text { Dar } \\
\mathrm{k} \\
\text { gre } \\
\text { en }\end{array}$ & 100 & $\begin{array}{l}6 \\
2 \\
4\end{array}$ & $\begin{array}{l}(34 \\
.50 \\
) \\
34 . \\
40\end{array}$ & $\begin{array}{l}(3 . \\
67) \\
3.5 \\
2\end{array}$ & $\begin{array}{l}(8.9 \\
4) \\
8.80\end{array}$ & $\begin{array}{l}(9 . \\
41) \\
9.3 \\
0\end{array}$ \\
\hline $\begin{array}{l}\text { Co } \\
\left(\mathrm{C}_{18} \mathrm{H}_{23} \mathrm{~N}\right. \\
\left.{ }_{4} \mathrm{O}_{7}\right)(\mathrm{NC} \\
\mathrm{S}) \mathrm{Br}\end{array}$ & $\begin{array}{l}\text { Pal } \\
\text { e } \\
\text { gre } \\
\text { en }\end{array}$ & 175 & $\begin{array}{l}6 \\
2 \\
2\end{array}$ & $\begin{array}{l}(37 \\
.75 \\
) \\
37 . \\
60\end{array}$ & $\begin{array}{l}(3 . \\
80) \\
3.7 \\
0\end{array}$ & $\begin{array}{l}(11 . \\
59) \\
11.4 \\
0\end{array}$ & $\begin{array}{l}(9 . \\
75) \\
9.6 \\
2\end{array}$ \\
\hline
\end{tabular}




\subsection{Physical measurements}

The structure of the ligand was determined by a combination of elemental analysis-NMR, IR and mass spectral data. Conductivity data of the complex was recorded using their $0.01 \mathrm{M}$ aqueous solution, with the help of a DDR Conductivity meter type 304. A Jeol D-300 (El/Cl) spectrometer was used for obtaining the mass spectra of the ligand hydrochlorides of low molecular weight. Infrared spectra in the range $4000-250 \mathrm{~cm}-1$ were recorded by Perkin Elmer infrared spectrometer in $\mathrm{KBr}$ pellets. FTIR spectra of a number of compound were recorded by Shimadzu 8201 PC (4000-350 cm-1) infrared spectrophotometer. The pmr spectra were taken in D2O solution and recorded on bruker DRX300 (300 MHz. PT NMR) using tetra methylsilane as an internal standard.

\subsection{Nuclear magnetic resonance spectra}

In the $1 \mathrm{H}-\mathrm{NMR}$-spectrum of $\mathrm{H} 2 \mathrm{~L}(\mathrm{C} 18 \mathrm{H} 24 \mathrm{~N} 4 \mathrm{O} 7)$ the $(\mathrm{N}-\mathrm{OH})$ proton appears as a singler at $\delta 12.09 \mathrm{ppm}$ which disappears uppn deuterium exchange; aromatic protons are observed at $\{7.30$ as a singlet.In the13C H NMR -spectrum of $\mathrm{H} 2 \mathrm{~L}((\mathrm{C} 18 \mathrm{H} 24 \mathrm{~N} 4 \mathrm{O} 7)$, the carbon resonance of the azomethine groups neighboringbenzo and hydroxylimino groups are found at $\delta 153.80$ and $151.50 \mathrm{ppm}$ respectively, at lower fields as given literature(6).

The 1 H-NMR-spectrum of [Co (C18H23N4O7)Br2]; shows significant chemical shift for the deuterium exchangeable hydrogen-bridging $(\mathrm{OH})$ proton at $\delta(17.40 \mathrm{ppm})$ in the lower field region, which can be assigned to the formation of desired complex. The 13C $\{\mathrm{H}\}$ NMR spectrum of Co $(\mathrm{C} 18 \mathrm{H} 23 \mathrm{~N} 4 \mathrm{O} 7) \mathrm{Br} 2$ generally resemble that observed for the free ligand.

Table-1.2: 1H-NMR-Spectral data for the dioxime and some of its complexes

\begin{tabular}{|c|c|c|c|c|}
\hline $\begin{array}{c}\text { S.N } \\
\text { o. }\end{array}$ & COMPOUND & O-H-O & $\begin{array}{l}- \\
\mathrm{OCH}_{2} \mathrm{C} \\
\mathrm{H}_{2} \mathrm{O}-\end{array}$ & Ar-H \\
\hline 1. & $\begin{array}{l}\left(\mathrm{C}_{18} \mathrm{H}_{24} \mathrm{~N}_{4} \mathrm{O}_{7}\right) \\
\text { Or }\left(\mathrm{H}_{2} \mathrm{~L}\right)\end{array}$ & - & $\begin{array}{l}4.10- \\
3.50(\mathrm{~m}, 1 \\
6 \mathrm{H})\end{array}$ & $\begin{array}{l}7.28(\mathrm{~s}, \\
2 \mathrm{H})\end{array}$ \\
\hline 2. & $\begin{array}{l}\mathrm{Co} \\
\left(\mathrm{C}_{18} \mathrm{H}_{23} \mathrm{~N}_{4} \mathrm{O}_{7}\right) \mathrm{B} \\
\mathrm{r}_{2}\end{array}$ & $\begin{array}{l}17.40(\mathrm{~s}, \\
2 \mathrm{H})\end{array}$ & $\begin{array}{l}3.90- \\
3.36(\mathrm{~m}, 1 \\
6 \mathrm{H})\end{array}$ & $\begin{array}{l}7.04(\mathrm{~s}, \\
2 \mathrm{H})\end{array}$ \\
\hline 3. & $\begin{array}{l}\mathrm{Co} \\
\left(\mathrm{C}_{18} \mathrm{H}_{23} \mathrm{~N}_{4} \mathrm{O}_{7}\right)( \\
\mathrm{NCS}) \mathrm{Br}\end{array}$ & $\begin{array}{l}17.32(\mathrm{~s}, \\
1 \mathrm{H})\end{array}$ & $\begin{array}{l}4.02- \\
3.50(\mathrm{~m}, 1 \\
6 \mathrm{H})\end{array}$ & $\begin{array}{l}7.10(\mathrm{~s}, \\
2 \mathrm{H})\end{array}$ \\
\hline
\end{tabular}

\subsection{Infrared spectra:}

The IR-spectrum of $(\mathrm{C} 18 \mathrm{H} 24 \mathrm{~N} 4 \mathrm{O} 7)$ H2L also provides additional data confirming the structure. The ligand shows no characteristic absorptions assignable to either $\mathrm{NH} 2$ or $(\mathrm{C}=\mathrm{O})$ function but it has a broad resonance at $3180 \mathrm{~cm}-1$ which can be attributed to $v(\mathrm{O}-\mathrm{H})$ of the oxime groups. The sharp and intence peak at $1650 \mathrm{~cm}-1$ is attributed to the stretching vibration of $(\mathrm{C}=\mathrm{N})$ groups attached to the oximegroups (7). The FAB+ (Fast atom bombardment positive, m-nitro $\mathrm{C} 6 \mathrm{H} 5 \mathrm{CH} 2 \mathrm{OH}$ as matrix) pattern observed for this compound shows both $[\mathrm{M}+1]+$ and $[\mathrm{M}+\mathrm{H} 2 \mathrm{O}+2]$ ions at $\mathrm{m} / \mathrm{z}-409$ and 428 respectively.

The broad vibrations at $3180 \mathrm{~cm}-1$ in the free ligand are shifted to $2410 \mathrm{~cm}-1$ in the complex [Co (C18H23N4O7)Br2] and can be attributed to the formation of an intramolecular hydrogen bond $(8,9)$. The stretching vibrations of azomethine groups at complex. The mass spectrum of this dibromocobalt (III) complex showed apeak at $\mathrm{m} / \mathrm{z} 624$ [M] and confirmed the proposed structure.

Table1.3: Main IR Spectral data for the dioxime and its complexes

\begin{tabular}{|l|lr|l|l|l|}
\hline $\begin{array}{l}\text { S.NO } \\
\cdot\end{array}$ & COMPOUND & $\begin{array}{l}\Delta(\mathbf{O} \\
-\mathbf{H}-- \\
\mathbf{H})\end{array}$ & $\begin{array}{l}\mathbf{N}(\mathbf{C}=\mathbf{N} \\
)\end{array}$ & $\begin{array}{l}\mathbf{N}(\mathbf{N} \\
-\mathbf{O})\end{array}$ \\
\hline 1. & $\left(\mathrm{C}_{18} \mathrm{H}_{24} \mathrm{~N}_{4} \mathrm{O}_{7}\right) . \quad \mathrm{Or}$ & - & 1650 & 980 \\
& $\left(\mathrm{H}_{2} \mathrm{~L}\right)$ & & 1610 & \\
\hline 2. & $\mathrm{Co}\left(\mathrm{C}_{18} \mathrm{H}_{23} \mathrm{~N}_{4} \mathrm{O}_{7}\right) \mathrm{Br}_{2}$ & $\begin{array}{l}240 \\
0\end{array}$ & 1616 & 945 \\
& & 241 & 1610 & 940 \\
\hline 3. & $\mathrm{Co}$ & 0 & 1570 & \\
& $\left(\mathrm{C}_{18} \mathrm{H}_{23} \mathrm{~N}_{4} \mathrm{O}_{7}\right)(\mathrm{NCS})$ & & & \\
\hline
\end{tabular}

$3180 \mathrm{~cm}-1[v(\mathrm{O}-\mathrm{H})(\mathrm{H} 2 \mathrm{~L})] ; \quad 2070 \mathrm{~cm}-1[\mathrm{v}(\mathrm{SCN}-)] ; 2175$ and $2165 \mathrm{~cm}-1$

\subsection{Mass Spectra:}

Mass spectral data and chemical analysis confirm (1:1) (metal: ligand) ratio. The $\mathrm{FAB}$ mass spectra of [Co $(\mathrm{C} 18 \mathrm{H} 23 \mathrm{~N} 4 \mathrm{O} 7)(\mathrm{NCS})(\mathrm{Br})$ showed the peaks as expected at $\mathrm{m} / \mathrm{z}-622[\mathrm{M}+\mathrm{H} 2 \mathrm{O}+1]$.The IR spectra of the complexes are similar to that of dibromo cobalt(III) complex expect for the presence of the (SCN) stretching vibrations as expected. The thiocyano groups may coordinate with cobalt through nitrogen or the sulphurdonar(10) .

\subsection{Solubility, Conductivity and Other Data:}

The compounds are highly soluble in water and generally in polar solvents like ethanol, methanol, DMF, DMSO etc. The colourof (C18H24N4O7). Or (H2L), Co (C18H23N4O7)Br2, 
Co $(\mathrm{C} 18 \mathrm{H} 23 \mathrm{~N} 4 \mathrm{O} 7)(\mathrm{CN}) \mathrm{Br}$ are Pale yellow ,Dark green and Pale green respectively. The complexes are thermally stable and decompose above 2000C $(11,12)$.

\section{CONCLUTIONS}

The synthesis of macrocyclic complexes In view of the importance of the macrocyclic chemistry, cobalt (II) complexes of several new categories of new quadridentate ligand 5,6-Benzo(15-crown-5)4,7-diaza deca-2,9-ethanedial dioxime $(\mathrm{C} 18 \mathrm{H} 24 \mathrm{~N} 4 \mathrm{O} 7)$ were synthesized. Template condensation of new quadridentate ligand 5,6-Benzo(15crown-5)4,7-diaza deca-2,9-ethanedial dioxime $(\mathrm{C} 18 \mathrm{H} 24 \mathrm{~N} 4 \mathrm{O} 7)$ with $\mathrm{CoBr} 2.6 \mathrm{H} 2 \mathrm{O}$ in dry acetone yielded the corresponding metal complexes such as Co $(\mathrm{C} 18 \mathrm{H} 23 \mathrm{~N} 4 \mathrm{O} 7) \mathrm{Br} 2]$ and then [Co $(\mathrm{C} 18 \mathrm{H} 23 \mathrm{~N} 4 \mathrm{O} 7) \mathrm{Br} 2]$ in aqueous hot methyl alcohol (1:8) yield the macrocyclic complex [Co (C18H23N4O7)(NCS)(Br).The macrocyclic ligands and their complexes have been characterized by elemental analysis, molecular weight determination, conductance, IR and NMR spectral studies. The spectral data suggested tetra coordinated state for cobalt (III), its geometry is tetrahedral. Conductivity data suggests that they behave as electrolytes. The formulation of the complexes has been established on the basis of chemical composition. The ligand and their complexes have been used as catalyst in many industries.

\section{REFERENCES}

[1]. Pederrson,C.J.,J.Am.Chem.Soc.93 (1967)7017.

[2]. Bajaj A.V.and Poonia,N.S.,Coord.Chem.Rev;87 (1988)55.

[3]. Gok,Y.,New,J.,Chem; 20(1996) 971, Welcher, F.j.,Org.Anal. Reagents3(1947) 154;Serin S.,Gok, Y.,Karabocek,S. and Gultekin, N.Analyst;119(1994)1629.

[4]. ThomasT.W.and Underhill,A.E.,Chem. Soc. Rev; 191972)99.

[5]. Gok,Y.,Org.Prep.Proced. Int.22 (1990)641.

[6]. Altin K.R., Klummp G.W., DekoningH.and Van Den Winkel, Y., Recl. Trav. Chem. Pays. Bas, 113 (1994) 329; Van Arkel B., Vander Baan J.L.,Balt S.,Bickelhaupt, F.,de Bolster W.G. and Klumpp, G.W.,Tetrahedron 51 (1995) 4161. [7]. Yamazaki N. and Hohokbe Y., Bull.Chem. Soc.Japan44 (1971) 63.

[8]. BlineR.andHadzi D.,J.Chem. Soc.(1958)4536.

[9]. Nakamoto K.,Infra red spectra of Inorganic and coordination compounds Wiley,Interscience, New York91970).

[10]. Sun L., Hammarstorm, L., Akermark, B. and Styring S., Chem. Soc. Rev; 30, 36 (2001).

[11]. McFarland S.A., Magde D., and Finney N.S., Inorg. Chem; 44, 4066 (2005). 